\title{
Microstructural Study of Neodmium Nickelate Doped with Strontium Synthesized by Gelatin Method
}

\author{
R. M. P. B. Oliveira, ${ }^{1,2}$ P. M. Pimentel, ${ }^{3}$ J. H. Araújo, ${ }^{4}$ D. M. A. Melo, ${ }^{1}$ \\ M. A. F. Melo, ${ }^{1}$ and A. E. Martinelli ${ }^{1}$ \\ ${ }^{1}$ Programa de Pós Graduação em Ciência e Engenharia de Materiais, Universidade Federal do Rio Grande do Norte, \\ 59078-970 Natal, RN, Brazil \\ ${ }^{2}$ Faculdade de Engenharia de Materiais, 68505-080 Marabá, PA, Brazil \\ ${ }^{3}$ Universidade Federal Rural do Semi-Árido, 59515-000 Angicos, RN, Brazil \\ ${ }^{4}$ Departamento de Física Teórica e Experimental, Universidade Federal do Rio Grande do Norte, 59078-970 Natal, RN, Brazil
}

Correspondence should be addressed to R. M. P. B. Oliveira; rosaneboliveira@gmail.com

Received 14 December 2012; Revised 22 February 2013; Accepted 24 March 2013

Academic Editor: Steven Suib

Copyright (C) 2013 R. M. P. B. Oliveira et al. This is an open access article distributed under the Creative Commons Attribution License, which permits unrestricted use, distribution, and reproduction in any medium, provided the original work is properly cited.

\begin{abstract}
In this work nickelate nanoparticles were synthesized using a simple and fast new route, which makes use of gelatin as an organic precursor in order to evaluate the performance of the synthesis method to obtain materials and the influence of the strontium replacement on the structural parameters of the powders. Samples of $\mathrm{Nd}_{2-x} \mathrm{Sr}_{x} \mathrm{NiO}_{4}(x=0$ and 0.4$)$ were calcined at 700 and $900^{\circ} \mathrm{C}$ at a heating of $10^{\circ} \mathrm{C} / \mathrm{min}$ for 4 hours. X-ray powder diffraction patterns were obtained for all the samples, and the Rietveld Method was applied in order to determine the crystallite size using Scherrer's equation, the lattice parameters, and phase concentration. The results obtained using these techniques confirmed that the main crystal structure consists of the distorted $\mathrm{K}_{2} \mathrm{NiF}_{4}$-type tetragonal $\mathrm{I} / \mathrm{mmm}$. In addition, scanning electron microscopy images revealed the formation of nanosized particles.
\end{abstract}

\section{Introduction}

In recent years, the search for new perovskite-type oxides has been intensified due to the wide range of properties such as dielectric [1], catalytic activity [2] and electrocatalytic [3], optical [4], and magnetic properties [5]. The synthesis of these materials requires methods that provide a high surface area and high homogeneity. There are several methods for synthesis of perovskites, which directly affect the properties of these systems, specifically in its texture and specific surface area, oxidation states of cations, and oxygen stoichiometry. Traditional methods of preparation of perovskite-like materials adopted usually mixtures of constituents of oxides, hydroxides, or carbonates. However, as these materials generally have large particle size, these steps often require repeated and mixtures prolonged heating at high temperatures to produce a homogenous material and comprising a single phase. To overcome the disadvantages of low specific surface and limited control of the microstructure inherent in high temperature processes, the precursors are generally obtained by processes such as sol-gel or coprecipitation of metal ions by precipitating agents such as hydroxides, cyanide, oxalate, and citrate ion, among others. Among the synthesis methods, the ceramic is the most widely used due to its simplicity but has the disadvantage of low specific area $[6,7]$.

Recently, a route has been developed for obtaining nanoscale materials using gelatin as the organic precursor that has the advantage of producing homogeneous and nanometric powders [8-10]. The procedure is the formation of colloidal dispersions between the gelatin and metal ions, which are connected gelatin coordinates groups such as $\mathrm{NH}_{2}$ and $\mathrm{COOH}$. The dispersion is subjected to heating to reduce volume and, consequently, formation of a gel which is subsequently calcined at a predetermined temperature for the decomposition of gelatin and formation of inorganic oxides. This study is focused on the preparation of solid solutions of neodymium nickelates doped with strontium by a method that makes use of gelatin as an organic precursor in order to 


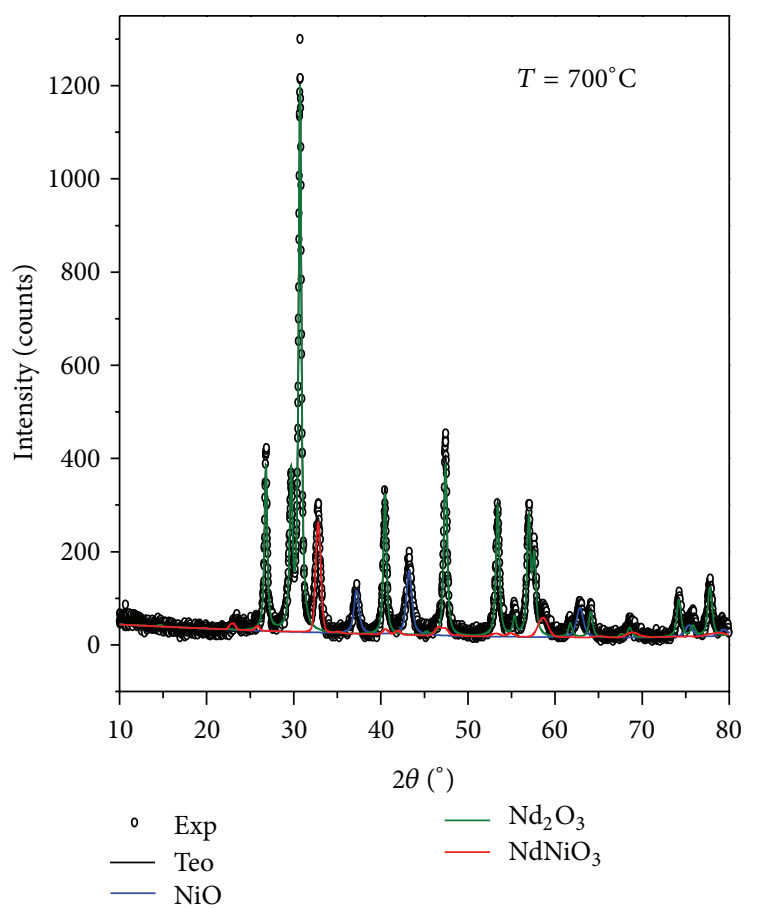

(a)

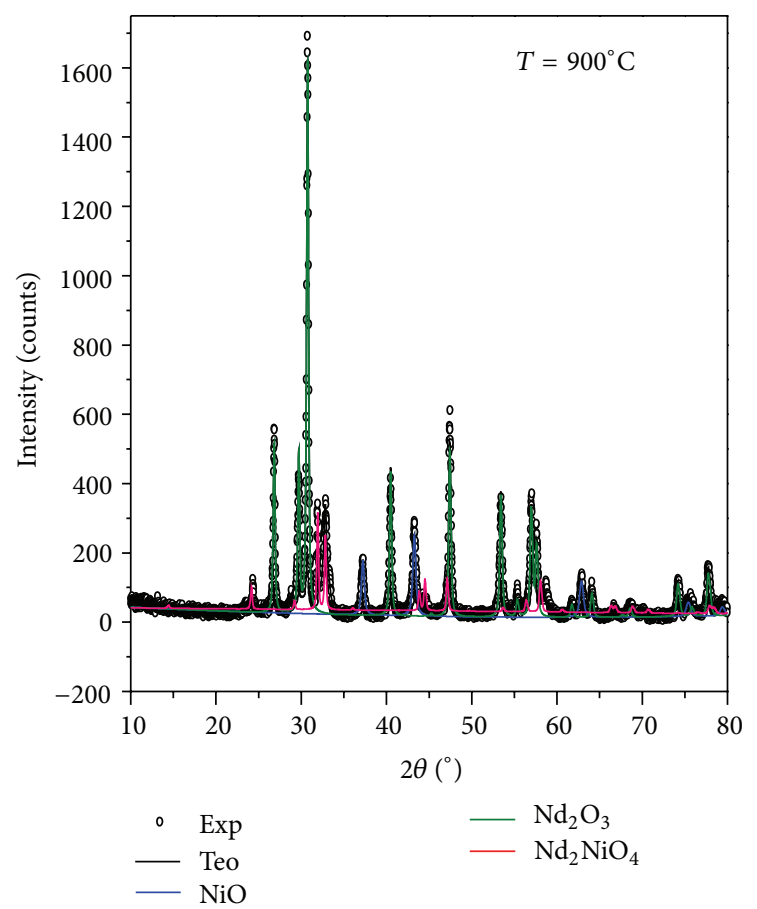

(b)

FIgURE 1: The Rietveld refinement of the system $\mathrm{Nd}_{2-x} \mathrm{Sr}_{x} \mathrm{NiO}_{4}$ to $x=0$ calcined at (a) $700^{\circ} \mathrm{C}$ and (b) $900^{\circ} \mathrm{C}$.

evaluate the structural properties of these oxides in function of increasing content of strontium and the heat treatment.

\section{Experimental}

Perovskites were prepared using gelatin as an organic precursor and metal nitrates as starting reagents. Gelatin was added to a beaker containing deionized water and stirred for 30 minutes at $50^{\circ} \mathrm{C}$. $\mathrm{Ni}\left(\mathrm{NO}_{3}\right)_{2} \cdot 6 \mathrm{H}_{2} \mathrm{O}(99.9 \%$, Sigma-Aldrich) and $\mathrm{Nd}\left(\mathrm{NO}_{3}\right)_{3} \cdot 6 \mathrm{H}_{2} \mathrm{O}(99.9 \%$, Sigma-Aldrich) were added to the solution at $70^{\circ} \mathrm{C}$ for several minutes. $\operatorname{Sr}\left(\mathrm{NO}_{3}\right)$ P.A. ( $\leq 99 \%$, Sigma-Aldrich) was added for further 30 minutes. The temperature was slowly increased to $90^{\circ} \mathrm{C}$, and the solution was stirred on a hot plate until a gel formed. The gel was then calcined at $350^{\circ} \mathrm{C}$ for 2 hours with a heating rate of $5^{\circ} \mathrm{C} \mathrm{min}^{-1}$. This resulted in a precursor powder, which was calcined at 700 and $900^{\circ} \mathrm{C}$ for 4 hours and characterized by $\mathrm{X}$-ray diffraction (XRD) and scanning electron microscopy (SEM) techniques.

X-ray patterns were obtained from samples calcined at different Sr concentrations and temperatures. Measurements were recorded on a Shimadzu XRD-6000 diffractometer with polychromatic radiation of $\mathrm{CuK} \alpha 1,2(\lambda 1=1.5406 \AA, \lambda 2=$ $1.5445 \AA$ ). A $2 \theta$ angular range was used between 10 and $90^{\circ}$ with a scan speed of $2^{\circ} \mathrm{min}^{-1}$ and step scan of $0.02^{\circ}$. Crystalline phases were identified using the International Center for Diffraction Data (ICDD) database. Crystallite sizes were obtained with Scherrer's equation. The Rietveld method was used to refine the XRD data using the MAUD program (version 2.044). The instrumental broadening has been used following the procedure as adopted by Lutterotti and Scardi [11]. The analyses were carried out by observing the plot of calculated and observed patterns. The morphology of the ceramic powders $\mathrm{Nd}_{2-x} \mathrm{Sr}_{x} \mathrm{NiO}_{4}(x=0$ and $x=0.4)$ calcined at 700 and $900^{\circ} \mathrm{C}$ was observed by SEM images obtained in a scanning electron microscope model SSX-550 from Shimadzu.

\section{Results and Discussions}

Figure 1 shows the observed and calculated X-ray powder patterns of crystallization products of the $\mathrm{Nd}_{2-x} \mathrm{Sr}_{x} \mathrm{NiO}_{4}(x=$ 0 ) powders calcined at $700^{\circ} \mathrm{C}$ and $900^{\circ} \mathrm{C}$. According to a refinement, there is a good agreement between experimental and refined diffraction, indicating that the results are highly reproducible and reliable; that is, the model parameters of crystal structure (low $R$ Bragg). The identified phases in the powder with $x=0$ were $\mathrm{Nd}_{2} \mathrm{O}_{3}$ hexagonal (JCPDS 41-1089), $\mathrm{NiO}$ cubic (JCPDS 73-1523), and $\mathrm{NdNiO}_{3}$ rhombohedral. In samples calcined at $900^{\circ} \mathrm{C}$ appears to $\mathrm{Nd}_{2} \mathrm{NiO}_{4}$ orthorhombic (JCPDS 21-1274). According to Zhao et al. (1996) [12], oxides with $\mathrm{A}_{2} \mathrm{BO}_{4}$ structure $\left(\mathrm{K}_{2} \mathrm{NiF}_{4}\right)$ are more stable then oxides with structure $\mathrm{ABO}_{3}$ when is doped with strontium.

Figure 2 shows the Rietveld refinement data for $\mathrm{Nd}_{2-x} \mathrm{Sr}_{x} \mathrm{NiO}_{4}(x=0.4)$ powder calcined at 700 and $900^{\circ} \mathrm{C}$. The result shows a good agreement between experimental and refined XRD patterns. Table 1 shows the refined parameters for $\mathrm{Nd}_{2-x} \mathrm{Sr}_{x} \mathrm{NiO}_{4}(x=0$ and 0.4$)$ powders calcined at 700 and $900^{\circ} \mathrm{C}$, respectively. The inclusion of strontium in the structure on $x=0.4$ favors the formation of 


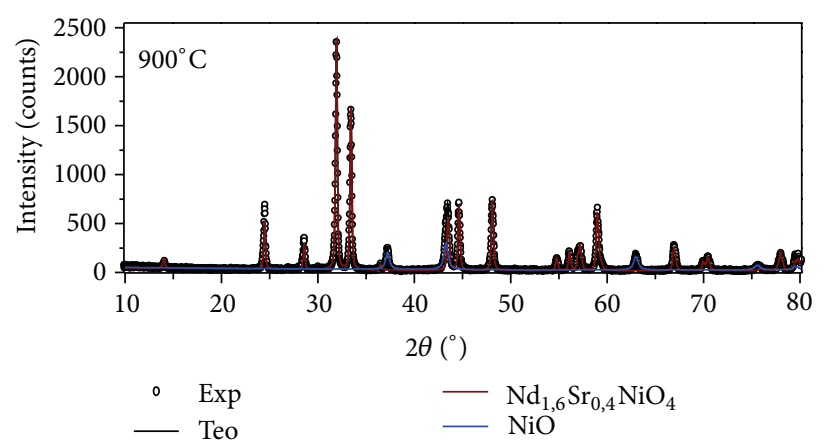

(a)

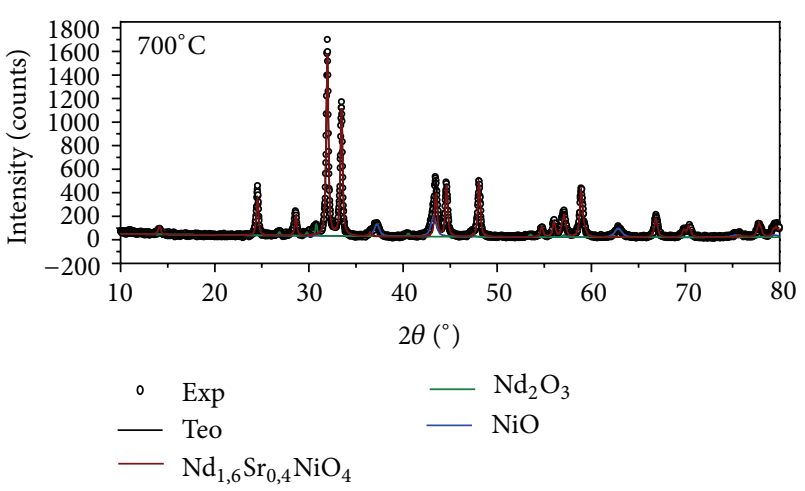

(b)

Figure 2: The Rietveld refinement of the system $\mathrm{Nd}_{1,6} \mathrm{Sr}_{0,4} \mathrm{NiO}_{4}$ calcined at 700 and $900^{\circ} \mathrm{C}$.

TABLE 1: Refinement parameters of system $\mathrm{Nd}_{2-x} \mathrm{Sr}_{x} \mathrm{NiO}_{4}$ to $x=0$ and $x=0.4$ calcined at $700^{\circ} \mathrm{C}$ and $900^{\circ} \mathrm{C}$.

\begin{tabular}{|c|c|c|c|c|c|c|c|c|c|}
\hline Sample & $R$ Bragg & Phase & ICSD & $\begin{array}{c}\text { Crystalline } \\
\text { system }\end{array}$ & $\begin{array}{l}\text { Space } \\
\text { Group }\end{array}$ & $\begin{array}{l}\text { Crystallite size } \\
(\mathrm{nm})\end{array}$ & $\begin{array}{c}a \\
(\AA) \\
\end{array}$ & $\begin{array}{l}b \\
\AA \\
\end{array}$ & $\begin{array}{l}c \\
\AA \\
\end{array}$ \\
\hline \multirow{3}{*}{$\begin{array}{l}\mathrm{Nd}_{2-x} \mathrm{Sr}_{x} \mathrm{NiO}_{4} \\
x=0 ; 700^{\circ} \mathrm{C}\end{array}$} & \multirow{3}{*}{11.5} & $\mathrm{Nd}_{2} \mathrm{O}_{3}$ & 32514 & Trigonal & $\mathrm{P}-3 \mathrm{ml}$ & 35.51 & 3.8302 & 3.8302 & 6.0046 \\
\hline & & $\mathrm{NiO}$ & 9866 & Cubic & $\mathrm{Fm}-3 \mathrm{~m}$ & 20 & 4.1791 & 4.1791 & 4.1791 \\
\hline & & $\mathrm{NdNiO}_{3}$ & 67722 & Orthorhombic & Pbnm:cab & 87.13 & 5.4311 & 5.4049 & 7.7910 \\
\hline \multirow{4}{*}{$\begin{array}{l}\mathrm{Nd}_{2-x} \mathrm{Sr}_{x} \mathrm{NiO}_{4} \\
x=0 ; 900^{\circ} \mathrm{C}\end{array}$} & \multirow{4}{*}{13.2} & $\mathrm{Nd}_{2} \mathrm{O}_{3}$ & 32514 & Trigonal & $\mathrm{P}-3 \mathrm{~m} 1$ & 68.30 & 3.8301 & 3.8301 & 6.0036 \\
\hline & & $\mathrm{NiO}$ & 9866 & Cubic & Fm-3m & 42.94 & 4.1793 & 4.1793 & 4.1793 \\
\hline & & $\mathrm{NdNiO}_{3}$ & 67722 & Orthorhombic & Pbnm:cab & 43.78 & 5.5115 & 5.4280 & 7.6705 \\
\hline & & $\mathrm{Nd}_{2} \mathrm{NiO}_{4}$ & 71137 & Orthorhombic & $\mathrm{Bmab}$ & 100 & 3.8054 & 12.3934 & 7.7910 \\
\hline \multirow{3}{*}{$\begin{array}{l}\mathrm{Nd}_{2-x} \mathrm{Sr}_{x} \mathrm{NiO}_{4} \\
x=0.4 ; 700^{\circ} \mathrm{C}\end{array}$} & \multirow{3}{*}{12.07} & $\mathrm{Nd}_{1,6} \mathrm{Sr}_{0,4} \mathrm{NiO}_{4}$ & 71138 & Tetragonal & $\mathrm{I} 4 / \mathrm{mmm}$ & 59.61 & 3.7831 & 3.7831 & 12.4603 \\
\hline & & $\mathrm{NiO}$ & 9866 & Cubic & Fm-3m & 23.91 & 4.1803 & 4.1803 & 4.1803 \\
\hline & & $\mathrm{Nd}_{2} \mathrm{O}_{3}$ & 32514 & Trigonal & $\mathrm{P}-3 \mathrm{ml}$ & 100 & 3.8272 & 3.8272 & 5.9910 \\
\hline \multirow{2}{*}{$\begin{array}{l}\mathrm{Nd}_{2-x} \mathrm{Sr}_{x} \mathrm{NiO}_{4} \\
x=0.4 ; 900^{\circ} \mathrm{C}\end{array}$} & \multirow{2}{*}{10.5} & $\mathrm{Nd}_{1,6} \mathrm{Sr}_{0,4} \mathrm{NiO}_{4}$ & 71138 & Tetragonal & $\mathrm{I} 4 / \mathrm{mmm}$ & 110 & 3.7840 & 3.7840 & 12.4584 \\
\hline & & $\mathrm{NiO}$ & 9866 & Cubic & P-3m1 & 64.79 & 4.1791 & 4.1791 & 4.1791 \\
\hline
\end{tabular}

TABLE 2: Quantitative analysis of samples obtained by MAUD refinement.

\begin{tabular}{lccc}
\hline Sample & Temperature $\left({ }^{\circ} \mathrm{C}\right)$ & \multicolumn{2}{c}{ Phase (\%) } \\
\hline $\begin{array}{l}\mathrm{Nd}_{2-x} \mathrm{Sr}_{x} \mathrm{NiO}_{4} \\
(x=0)\end{array}$ & \multirow{2}{*}{$\mathrm{Nd}_{2} \mathrm{O}_{3}$} & 65 \\
& & $\mathrm{NiO}$ & 21 \\
& & $\mathrm{NdNiO}_{3}$ & 14 \\
$\mathrm{Nd}_{2-x} \mathrm{Sr}_{x} \mathrm{NiO}_{4}$ & 900 & $\mathrm{Nd}_{2} \mathrm{O}_{3}$ & 58 \\
$(x=0)$ & & $\mathrm{NiO}$ & 19.5 \\
& & $\mathrm{NdNiO}_{3}$ & 12 \\
& & $\mathrm{Nd}_{2} \mathrm{NiO}_{4}$ & 10.5 \\
\hline $\mathrm{Nd}_{2-x} \mathrm{Sr}_{x} \mathrm{NiO}_{4}$ & 700 & $\mathrm{Nd}_{1.6} \mathrm{Sr}_{0.4} \mathrm{NiO}_{4}$ & 77.5 \\
$(x=0.4)$ & $\mathrm{NiO}$ & 20 \\
& & $\mathrm{Nd}_{2} \mathrm{O}_{3}$ & 2.5 \\
\hline $\mathrm{Nd}_{2-x} \mathrm{Sr}_{x} \mathrm{NiO}_{4}$ & \multirow{2}{*}{900} & $\mathrm{Nd}_{1.6} \mathrm{Sr}_{0.4} \mathrm{NiO}_{4}$ & 80 \\
$(x=0.4)$ & $\mathrm{NiO}$ & 20 \\
\hline
\end{tabular}

$\mathrm{Nd}_{2-x} \mathrm{Sr}_{x} \mathrm{NiO}_{4}$ tetragonal (JCPDS 80-2324) and $\mathrm{NiO}$ cubic (JCPDS 73-1523). For calcination at $900^{\circ} \mathrm{C}$, Figure 2(b), for $x=0.4$, shows $\mathrm{Nd}_{2-x} \mathrm{Sr}_{x} \mathrm{NiO}_{4}$ tetragonal (JCPDS 80-2324) and $\mathrm{NiO}$ cubic (JCPDS 73-1523). It is known that the substitution in the perovskite-type oxide of a trivalent metal ion in the A site for a bivalent or tetravalent metal cation $\left(A^{\prime}\right)$ is accompanied by a change in the oxidation state of the site $B$ metal cation by modifying the activity catalyst. However, the change in oxidation state of the B site cation in the insertion of $\mathrm{A}^{\prime}$ is accompanied by the formation of structural defects.

It is observed that the lattice parameter for the $\mathrm{NdNiO}_{3}$ decreases due to oxidation of $\mathrm{Ni}^{2+}$ to $\mathrm{Ni}^{3+}$ compared with system $\mathrm{Nd}_{2} \mathrm{NiO}_{4}$ when it is calcined at $900^{\circ} \mathrm{C}$. It was reported that the substitution of $\mathrm{Nd}$ with $\mathrm{Sr}$ in $\mathrm{Nd}_{2} \mathrm{NiO}_{4}$ might induce a structural phases transition from orthorhombic to tetragonal symmetry leading to a mixed valence $\left(\mathrm{Ni}^{2+} / \mathrm{Ni}^{3}\right)$ for the transition metal ion, which would in turn induce interesting electrical and magnetic properties in this system [13]. Moreover, increasing the lattice parameter $c$ is due to replacement of ion $\mathrm{Nd}^{3+}$ with $\mathrm{Sr}^{2+}$ ion, promoting the removal of the layers in the structure of perovskite [14]. The quantitative phase analysis of samples obtained by MAUD program is given in Table 2 . 


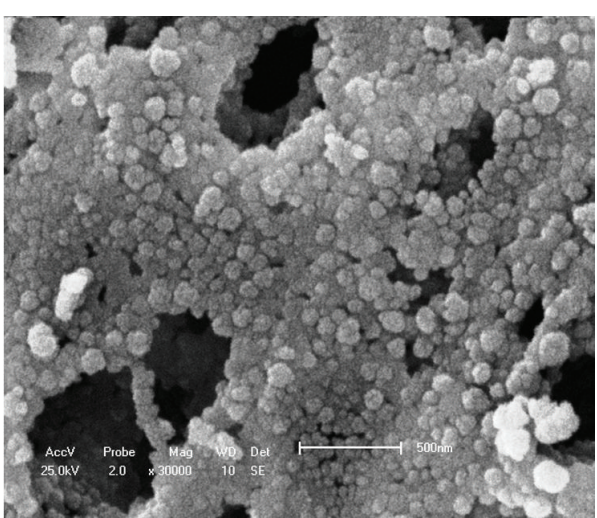

(a)

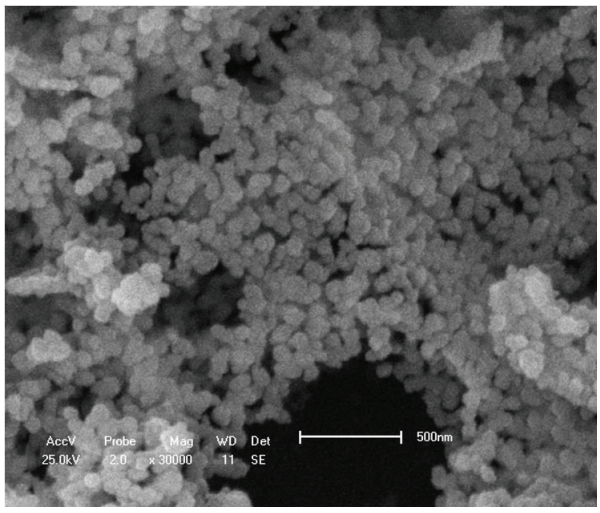

(c)

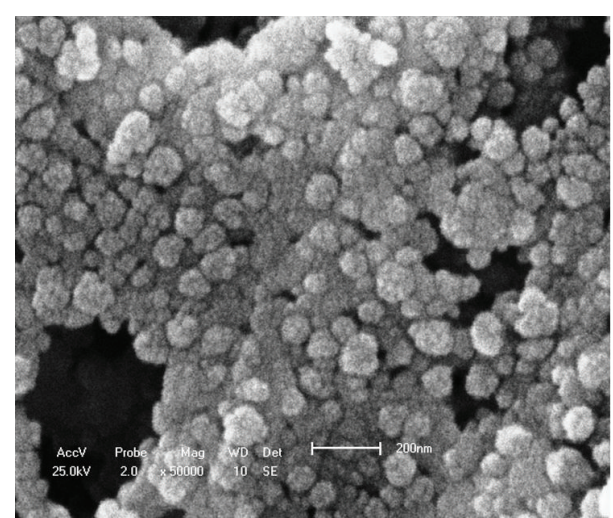

(b)

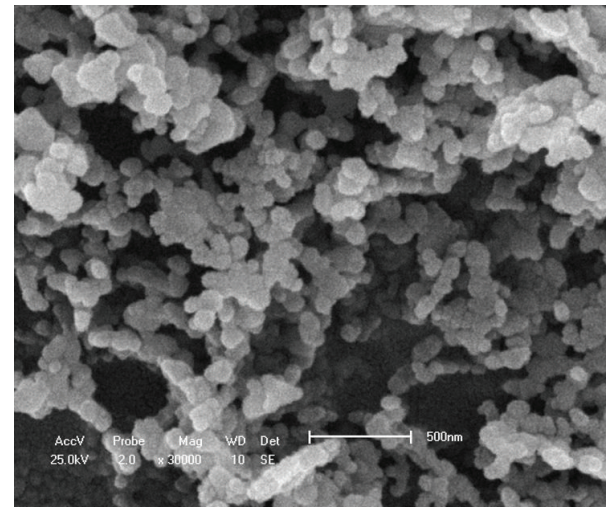

(d)

Figure 3: (a) SEM image of system $\mathrm{Nd}_{2-x} \mathrm{Sr}_{x} \mathrm{NiO}_{4}$ to $x=0$ calcined at $700^{\circ} \mathrm{C}$; (b) $\mathrm{Nd}_{1,6} \mathrm{Sr}_{0,4} \mathrm{NiO}_{4}$ calcined at $700^{\circ} \mathrm{C}$; (c) $\mathrm{Nd}_{2-x} \mathrm{Sr}_{x} \mathrm{NiO}_{4}$ to $x=0$ calcined at $900^{\circ} \mathrm{C}$; (d) $\mathrm{Nd}_{1,6} \mathrm{Sr}_{0,4} \mathrm{NiO}_{4}$ calcined at $900^{\circ} \mathrm{C}$.

The morphology of the ceramic powders synthesized was determined by SEM images shown in Figure 3. By means of these images, it is observed that the particles have a rounded shape and uniform distribution of particle size. The particles are very small (less than $100 \mathrm{~nm}$ ), and this is evident in all images corresponding to the $\mathrm{Nd}_{2-x} \mathrm{Sr}_{x} \mathrm{NiO}_{4} \quad(x=0$ and $x=$ 0.4 ) powders calcined at 700 and $900^{\circ} \mathrm{C}$.

The porous material has been generated during the evolution of gases formed from the decomposition of the gelatin during the calcination step. As shown in Figure 3(d), the quantity and pore size decrease with increasing temperature of calcination; this is a consequence of the phenomenon which leads to sintering of the agglomerated particles.

\section{Conclusions}

The synthesis route using gelatin was feasible for the synthesis of nanosized and porous ceramic powders, since it is a polymeric material containing groups which can coordinate with the metal ions as well as being a material of low cost and nontoxic.

The ceramic powders calcined under the conditions formed a solid solution whose main phase was perovskitelike for powders with partial replacement of $\mathrm{Nd}^{+2}$ metal ion with $\mathrm{Sr}^{+3}$. In addition there were no significance differences in the structures of these powders calcinated at $T=700^{\circ} \mathrm{C}$ and $900^{\circ} \mathrm{C}$.

\section{Acknowledgments}

The authors are grateful to the Brazilian agencies Capes and $\mathrm{CNPq}$ for the financial support and GELITA for supplying the gelatin.

\section{References}

[1] C. P. L. Rubinger, R. L. Moreira, G. M. Ribeiro et al., "Intrinsic and extrinsic dielectric responses of $\mathrm{CaCu}_{3} \mathrm{Ti}_{4} \mathrm{O}_{12}$ thin films," Journal of Applied Physics, vol. 110, no. 7, Article ID 074102, 2011.

[2] R. Hu, R. Ding, J. Chen, J. Hu, and Y. Zhang, "Preparation and catalytic activities of the novel double perovskite-type oxide $\mathrm{La}_{2} \mathrm{CuNiO}_{6}$ for methane combustion," Catalysis Communications, vol. 21, pp. 38-41, 2012.

[3] A. Galal, N. F. Atta, S. A. Darwish, A. A. Fatah, and S. M. Ali, "Electrocatalytic evolution of hydrogen on a novel $\mathrm{SrPdO}_{3}$ perovskite electrode," Journal of Power Sources, vol. 195, no. 12, pp. 3806-3809, 2010.

[4] D. T. M. Huong, N. H. Nam, L. V. Vu, and N. N. Long, "Preparation and optical characterization of $\mathrm{Eu}^{3+}$-doped $\mathrm{CaTiO}_{3}$ perovskite powders," Journal of Alloys and Compounds, vol. 537, pp. 54-59, 2012. 
[5] J. Fan, B. Hong, L. Zhang et al., "Heisenberg-like ferromagnetism and percolative conductivity in the half-doped manganite $\mathrm{Nd}_{0.5} \mathrm{Ca}_{0.25} \mathrm{Sr}_{0.25} \mathrm{MnO}_{3}$," Journal of Magnetism and Magnetic Materials, vol. 322, no. 22, pp. 3692-3695, 2010.

[6] F. Li, H. Zheng, D. Jia, X. Xin, and Z. Xue, "Syntheses of perovskite-type composite oxides nanocrystals by solid-state reactions," Materials Letters, vol. 53, no. 4-5, pp. 282-286, 2002.

[7] C. Xiulan and L. Yuan, "New methods to prepare ultrafine particles of some perovskite-type oxides," Chemical Engineering Journal, vol. 78, no. 2-3, pp. 205-209, 2000.

[8] N. A. S. Nogueira, E. B. da Silva, P. M. Jardim, and J. M. Sasaki, "Synthesis and characterization of $\mathrm{NiAl}_{2} \mathrm{O}_{4}$ nanoparticles obtained through gelatin," Materials Letters, vol. 61, no. 25, pp. 4743-4746, 2007.

[9] A. S. de Menezes, C. M. R. Remédios, J. M. Sasaki et al., "Sintering of nanoparticles of $\alpha-\mathrm{Fe}_{2} \mathrm{O}_{3}$ using gelatin," Journal of Non-Crystalline Solids, vol. 353, no. 11-12, pp. 1091-1094, 2007.

[10] P. M. Pimentel, R. M. P. B. Oliveira, J. H. Araújo, F. S. Oliveira, O. R. Bagnato, and D. M. A. Melo, "Synthesis and structural characterization of Sm-Sr nickelates," Journal of Chemistry and Chemical Engineering, vol. 6, p. 526, 2012.

[11] L. Lutterotti and P. Scardi, "Simultaneous structure and sizestrain refinement by the Rietveld method," Journal of Applied Crystallography, vol. 23, p. 246, 1990.

[12] Z. Zhao, X. Yang, and Y. Wu, "Comparative study of Nickelbased perovskite-like mixed oxide catalysts for direct decomposition of NO," Applied Catalysis B, vol. 8, no. 3, pp. 281-297, 1996.

[13] B. W. Arbuckle, K. V. Ramanujachary, Z. Zhang, and M. Greenblatt, "Investigations on the structural, electrical, and magnetic properties of $\mathrm{Nd}_{2-x} \mathrm{Sr}_{x} \mathrm{NiO}_{4+\delta}$, Journal of Solid State Chemistry, vol. 88, no. 1, pp. 278-290, 1990.

[14] M. Zaghrioui, F. Giovannelli, S. Pruvost, N. Poirot, and I. Monot-Laffez, "Magnetic and transport properties of $\mathrm{Nd}_{1.67} \mathrm{Sr}_{0.33} \mathrm{NiO}_{4}$," Journal of Magnetism and Magnetic Materials, vol. 305, no. 1, pp. 71-75, 2006. 

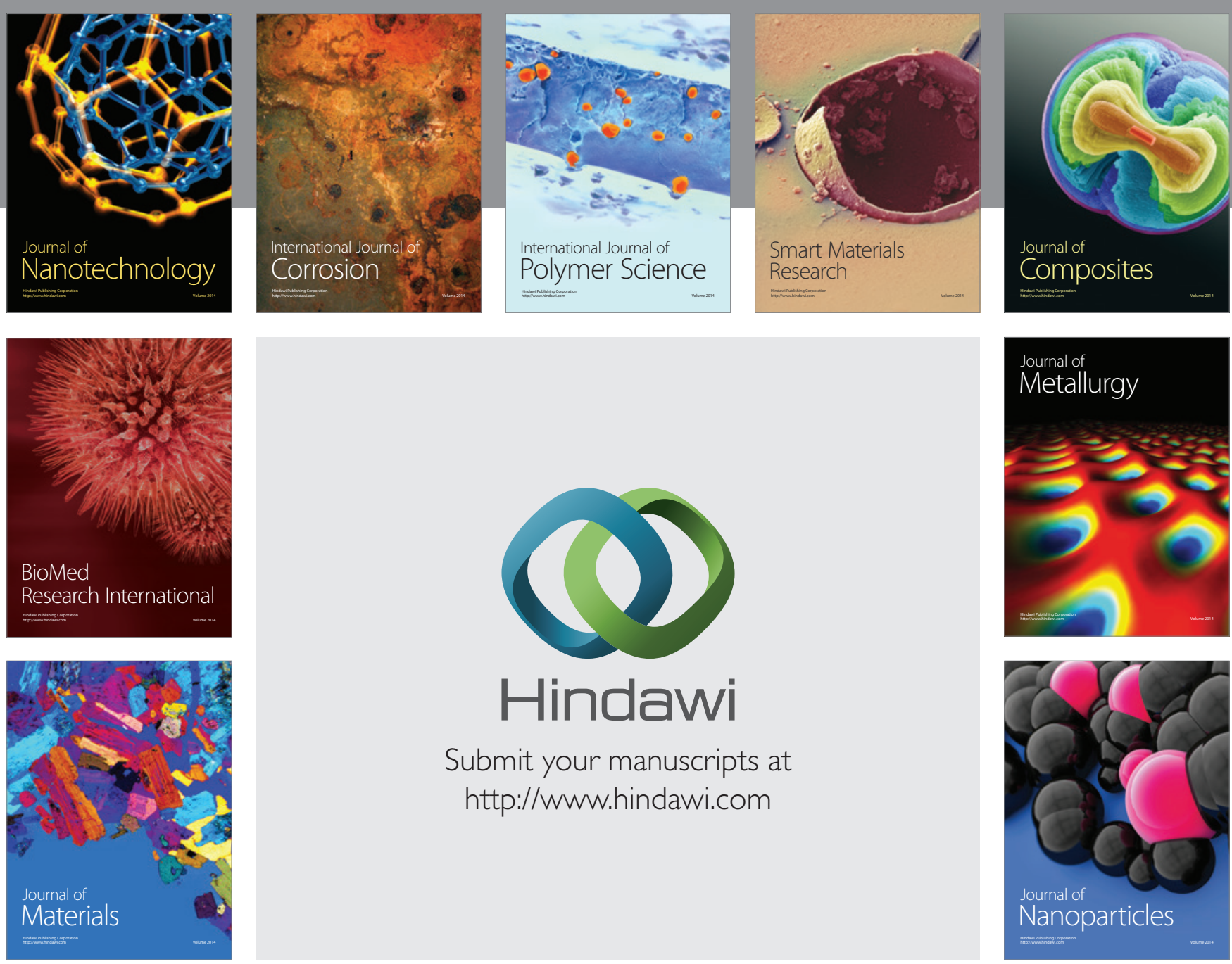

Submit your manuscripts at http://www.hindawi.com
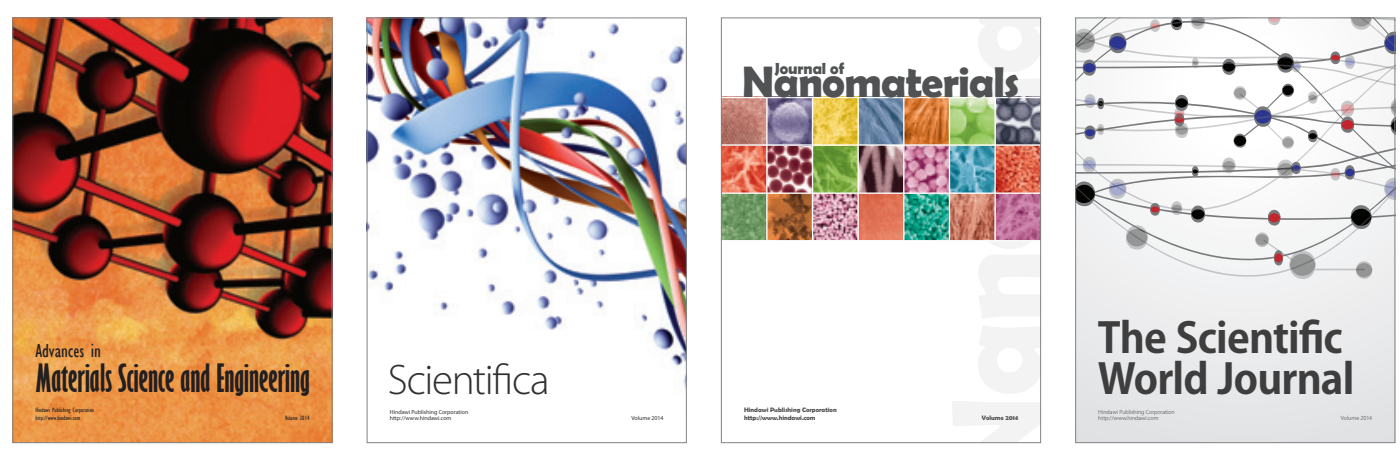

\section{The Scientific World Journal}
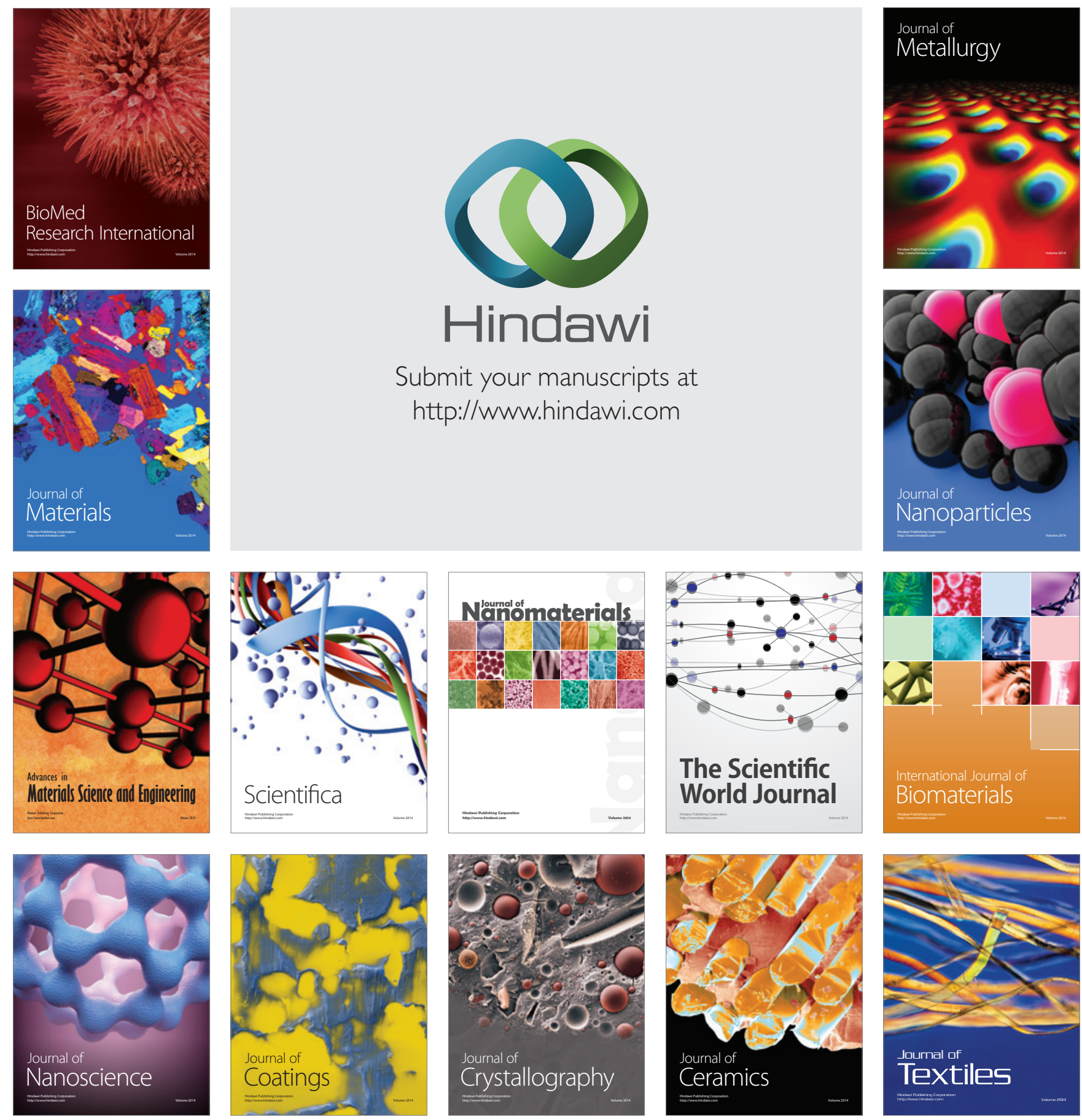